\title{
As marcas da pantera, 25 anos depois...
}

The panther marks, 25 years later...

Las marcas de la pantera, 25 años después...

\author{
Margareth Rago \\ Universidade Estadual de Campinas (Brasil) \\ http://orcid.org/0000-0003-4768-9696 \\ http://lattes.cnpq.br/3274637598730008 \\ ragomargareth@gmail.com
}

\section{Resumo}

25 anos após a publicação do artigo "As Marcas da Pantera: Michel Foucault na Historiografia Brasileira", Foucault continua a nos surpreender com suas ousadas reflexões. Recentemente publicado, o livro As confissões da carne completa sua genealogia do sujeito moderno, apontando para dimensões profundamente enraizadas em nossa psique. Sua pesquisa arqueogenealógica sobre os regimes de verdade que regem nossas vidas, amplia-se ao abranger os primeiros anos do cristianismo e ao revelara dívida que este mantém com o estoicismo. Em seus cursos, Foucault traz contundentes reflexões sobre a migração da confissão e do poder pastoral para fora dos muros da igreja e para sua incorporação no Estado moderno, chegando aos nossos dias, marcados pelo neoliberalismo. Coma noção de governo de si e do outro, problematiza novas tecnologias do poder, enquanto as "contracondutas" remetem à maneira pela qual as práticas da liberdade são experimentadas frente à governamentalidade cristã ou neoliberal.

Palavras-chave: Foucault. Governamentalidade. Contracondutas. 


\begin{abstract}
25 years after the publication of the article "The Panther Marks: Michel Foucault in the Brazilian Historiography", Foucault keeps surprising us with his daring reflections. Recently published, the book The confessions of the flesh completes his genealogy of the modern man, pointing out the dimensions deeply rooted in our psyche. His archeo-genealogical history about the real regimes that run our lives is extended while reaching the early years of Christianism and revealing the debt it maintains with Stoicism. In his courses, Foucault brings forceful reflections about the migration of confession and pastoral power outside the church walls and its incorporation into the modern State, until nowadays, marked by the neoliberalism. How the notion of one's self and self-government problematizes new technologies of power while the "counter-conducts" remit to how freedom practices are experienced in the face of Christian or neoliberal governmentality.
\end{abstract}

Keywords: Foucault. Governmentality. Counter-conducts.

\title{
Resumen
}

Pasados 25 años de la publicación del artículo "As Marcas da Pantera: Michel Foucault na Historiografia Brasileira", Foucault sigue sorprendiéndonos con sus osadas reflexiones. Recién publicado, el libro As confissões da carne completa su genealogía del sujeto moderno, con apuntes a dimensiones profundamente difundidas en nuestra psique. Su investigación arqueo genealógica sobre los regímenes de verdad que rigen nuestras vidas, se amplia al abarcar los primeros años del cristianismo y a la deuda que este mantiene con el estoicismo. En sus cursos, Foucault trae contundentes reflexiones sobre la migración de la confesión y del poder pastoral a fuera de los muros de la iglesia y para su incorporación en el Estado moderno, llegando a nuestros días, marcados por el neoliberalismo. Con la noción de gobierno de si y del otro, problematiza las nuevas tecnologías del poder, mientras las "contraconductas" remiten a la manera por la cual las prácticas de la libertad son experimentadas frente a la gobernabilidad cristiana o neoliberal.

Palabras-clave: Foucault. Gobernabilidad. Contraconductas. 
[...] o que, na história, escapa à história não é o universal, o imóvel, aquilo que todo mundo, todo o tempo, pode pensar, dizer ou querer. O que escapa à história é o instante, a fratura, o dilaceramento, a interrupção.

Michel Foucault

\section{- um desafio para a história}

Muitas décadas atrás, Michel Foucault desafiou radicalmente a produção do conhecimento histórico, ao criticar contundentemente seus modos de operar e os conceitos e as categorias a partir das quais eram produzidas as narrativas históricas hegemônicas. Antes mesmo que os "estudos feministas" e os "estudos pós-coloniais" questionassem os discursos masculinos, brancos e centristas, de onde partia a produção das leituras sobre o passado, o filósofo francês propunha uma história genealógica, na esteira de Nietzsche, destacando que os objetos históricos não eram realidades materiais pré-discursivas; ao contrário, eram engendrados pelos próprios discursos que diziam representá-los. Contrariando a "teoria do reflexo", predominante nos anos sessenta, o discurso passava a ser pensado como materialidade, como "prática discursiva" que institui a realidade de que fala. Foucault inaugurava um novo modo de pensar e de escrever a história, como procurei mostrar em "As marcas da pantera: Foucault para historiadores", texto publicado em 1993, que retomo nesse momento.

Vinte e cinco anos depois, pode-se avaliar com segurança que as proposições foucaultianas produziram efeitos extremamente ricos na produção do conhecimento histórico, e que reverberaram igualmente em muitas outras áreas do conhecimento, já que o próprio filósofo questionava as tradicionais divisões das disciplinas acadêmicas. Hoje, perguntamonos o que seria da História sem a Geografia, a Arquitetura, a História da Medicina, a Psicologia, a Psicanálise, a Literatura, as Artes Visuais, o Jornalismo e toda uma série de saberes que nos permitem afirmar a importância da transversalidade e a necessidade do diálogo entre diferentes modos de conhecer. E, inversamente, o que seria de todos esses saberes sem um novo conceito de História?

As contribuições de Foucault para os/as historiadores/as foram imensas, mas é bom notar que se conjugaram com inúmeras provocações e aportes de outros conhecidos filósofos, como Gilles Deleuze e Jacques Derrida e de outros campos do saber, em um contexto de profundas transformações políticas, sociais e culturais. O mundo já não era o mesmo desde meados dos anos sessenta e pedia novos olhares, outros modos de pensar e formas de existência mais humanizadas, como manifestavam os movimentos da contracultura, o feminismo, o movimento hippie, os movimentos estudantis estadunidenses, referenciados pela New Left e especialmente, o impactante Civil Rights Movement. Em 1967, ano em que Foucault palestrava para os arquitetos franceses, abrindo o espaço com sua noção de "heterotopia", Caetano Veloso cantava "Alegria, Alegria", inaugurando o Tropicalismo, no Brasil.

Falando especificamente de Foucault, a conviç̧ão de que a tarefa urgente para o intelectual comprometido com o seu tempo é a crítica do presente, uma "ontologia histórica de nós mesmos" foi esclarecedora. Há que se entender que um "diagnóstico da nossa atualidade", como afirma no famoso texto intitulado "O que são as Luzes?", de 1984, não poderia realizar-se sem a crítica histórica do passado, sem a historicização das formas que constituem nosso tempo, chamado de Modernidade tardia, reflexiva ou de Pós-modernidade, assim como das racionalidades que o presidem, naturalizam e legitimam. 
Para entender quem somos e como chegamos a ser o que somos, seria então necessário “tornar visível o que é visível”, como diz esse filósofo-historiador em relação à função do intelectual ${ }^{1}$, mas também seria preciso convocar o conhecimento histórico em uma outra direção, capaz de mostrar as origens nos jogos de poder, nos conflitos das disputas de diferentes atores e regimes de verdade, dando visibilidade às feridas conflitantes e originárias, que se tornaram cicatrizes profundas, incrustadas na pele, continuamente reabertas e remexidas pela violência que se aprimora nas inúmeras formas de exclusão e de humilhação racial, sexual, classista e geracional. Trata-se, portanto, de desnaturalizar o presente, abrindo-o para transformações necessárias e possíveis das condições que imperam na atualidade. Como diz Foucault, "o genealogista necessita da história para conjurar a quimera da origem" (1979: 19).

Vivemos em um mundo em que o capitalismo empresarial aprimorou e sofisticou incrivelmente seus modos de controle e de governo da população e do indivíduo, chegando a visar a própria constituição genética de cada um, de maneira ainda mais minuciosa, requintada e científica. Em outras palavras, continuando o que aprendemos com esse filósofo, vinte e cinco anos atrás, não é mais possível pensar nas origens como "começos nobres" de que decorrem linhas de continuidade, atestando nosso progresso constante. É preciso "rir das origens", partindo dos "começos baixos", como disse Nietzsche e como propõe a genealogia de Foucault, autor que continua revolucionando a História, como dissera, tempos atrás, Paul Veyne.

Mas falar da História hoje, das tarefas do historiador e da historiadora, é o mesmo que nas décadas de 1980 e 1990? Certamente, a produção do conhecimento histórico se transformou incrivelmente, abrindo-se para temas inimagináveis, sob a pressão dos movimentos dos excluídos, das mulheres, das feministas, dos negros, dos indígenas, dos trabalhadores pobres, chegando aos loucos, aos presos, aos "anormais", enfim, aos inúmeros atores que demanda(ra)m visibilidade de seu protagonismo social, o que inclui tratar da violência de que foram - ou ainda são - vítimas, ao longo do tempo. A História deixou de ser um mero relato dos acontecimentos do passado, para trabalhar criticamente com os problemas da contemporaneidade, que pedem urgentes esclarecimentos, leituras, interpretações e respostas. Deixou de visar a produção de uma narrativa totalizante que aponta para um futuro utópico, visto como necessidade inelutável do desenvolvimento das forças produtivas.

Além do mais, um novo tipo de intelectual, chamado por Foucault de "intelectual específico" entrou em cena, recusando o lugar de detentor da verdade, de condutor das massas e de portador universal da revolução. Ao mesmo tempo, a história genealógica revelou a procedência do "intelectual universal", descendente do pastor cristão. Como analisa Priscila Piazentini Vieira, em seu livro A coragem da Verdade e a Ética do Intelectual em Michel Foucault (2015), a emergência da figura do "intelectual específico" supõe uma nova relação com a verdade e com a vida, implica a atitude crítica e a prática da "parresia", ou coragem da verdade diante dos modos excludentes, hierárquicos e dissociados, que prevalecem em nosso mundo e que corroem as nossas vidas.

Contudo, mais do que os indivíduos e as coletividades que pressiona(ra)m para serem reconhecidos, muitos temas antes naturalizados foram desconstruídos e incorporados na produção do conhecimento histórico. Se, desde meados da década de 1970, passamos a conhecer histórias do corpo, da sexualidade e da subjetividade, aliás, com o próprio trabalho de Foucault, em Surveiller et Punir (1975) e Histoire de la Sexualité, vol. I La volonté de savoir (1976), muitos outros domínios entraram para o campo da História, extrapolando as tradicionais divisões hierárquicas entre público e privado, razão e emoção, cultura e natureza.

\footnotetext{
1 “ (...) o intelectual, hoje, não me parece ter tanto o papel de dizer verdades proféticas para o futuro [...]. Por meio do pequeno gesto que consiste em deslocar o olhar, ele torna visível o que é visível, faz aparecer o que está tão próximo, tão intimamente ligado a nós que, por isso mesmo, não o vemos" (FOUCAULT, 2011b: 246).
} 
A título de exemplo, Alain Corbin, inspirado nesse filósofo, brindou-nos, dentre outros estudos, com uma história do cheiro, em Le miasme et la jonquille: L'odorat et l'imaginaire social, XVIIIe-XIXe siècles (1982), traduzido no Brasil, como Saberes e Odores: o olfato e o imaginário social nos séculos XVIII e XIX (1987). Recentemente, publicou uma história da relação que temos mantido com a árvore, fonte de emoções desde a Antiguidade aos nossos dias, intitulada La douceur de l'ombre (2013), e ainda a Histoire du Silence: de la Renaissance à nos jours (2016).

Desfazendo oposições binárias que separam o público e o privado, para o que também muito contribuíram os "estudos feministas", referenciados pela filosofia da diferença, Michelle Perrot nos trouxe sua Histoire des Chambres (2009), publicada no Brasil, como História dos Quartos (2013), ampliando sua enorme contribuição à História da Vida Privada, organizada, na França, por Philippe Ariès e Georges Duby. Vale notar que na "Introdução" desse novo livro, a famosa historiadora destaca a indicação de Foucault, ao propor uma história dos espaços, questionando a noção de que a história deveria ocupar-se do tempo, enquanto a Geografia se voltaria para o espaço. Ao construir novas representações do tempo e do espaço e, enfrentando seu inevitável entrecruzamento com suas noções de "heterotopia" e de "heterocronia", Foucault sugeria: "Dever-se-ia escrever uma história dos espaços - que seria ao mesmo tempo uma história dos poderes, desde as grandes estratégias da geopolítica até as pequenas táticas do habitat (...)" (FOUCAULT apud PERROT, 2011: 16). A resposta de Michelle Perrot não tardou a chegar.

\section{- novos temas, novas atitudes}

Nos anos noventa, ainda não haviam sido publicados muitos dos cursos de Foucault, falecido em 1984. Foi somente no século XXI, que tivemos conhecimento, entre outros, de $A$ Hermenêutica do Sujeito (2004), Em defesa da sociedade (2005), O poder psiquiátrico (2006), Nascimento da Biopolítica (2008), Segurança, Território e População (2008), A coragem da verdade (2011), Mal faire, Dire vrai (2012), Do governos dos vivos (2014), Dits e Ecrits (1994), em quatro volumes, em francês e em dez volumes, na tradução brasileira. Em 2018, são lançados o volume IV da Histoire de la Sexualité. Les Confessions de la Chair ${ }^{2}$, em vias de ser traduzido para o português e La Sexualité, Discours sur la Sexualité.

Ora, trata-se de uma produção extensíssima que desconhecíamos vinte e cinco anos atrás e que obviamente também altera nossa leitura da obra de Foucault, além de nos dotar de novos conceitos e de outras problematizações para pensar criticamente o presente. Em relação a este primeiro ponto, pode-se dizer que as interpretações construídas sobre sua produção se confirmaram e se aprofundaram; além disso, ficou mais claro seu engajamento político com a nossa atualidade.

Nessa direção, vale dizer que, para Foucault, não se tratava apenas de propor uma “analítica do poder", vendo o poder em sua positividade, mostrando suas diferenças, enquanto poder disciplinar, biopoder, biopolítica e governamentalidade, o que foi realmente uma grande novidade inclusive para a Ciência Política, habituada a pensar o Estado e os regimes políticos, mas não as formas de poder e controle operacionalizadas sobre os corpos dos governados. Ao contrário do que afirmavam seus críticos apressados, segundo os quais Foucault só se preocupava com o poder, ele trouxe outras possibilidades de pensar também "as práticas da liberdade", já que poder e liberdade participam de jogos relacionais, em suas análises. Têm-se repetido e desdobrado suas explicações de que "onde há poder, há resistência", e de que "se não houvesse resistência, não haveria relações de poder"

\footnotetext{
${ }^{2}$ Veja-se a resenha de Alessandro Francisco "As confissões da carne”, publicada na revista Ecopolítica, da PUC-SP, n. 21.2018. Disponível em: https://revistas.pucsp.br/index.php/ecopolitica/article/view/40055. Acesso em 06 abr. 2020.
} 
(FOUCAULT, 2004b: 268), assim como as diferenciações que estabelece entre dominação e poder (GRABOIS, 2011). Para o filósofo, em estados de dominação, como o totalitarismo e a escravidão, há pouco espaço para que as relações de poder se manifestem, já que, sendo assimétricas, elas estão bloqueadas e congeladas, inviabilizando as práticas da liberdade (FOUCAULT, 1994b: 711).

Obviamente para este crítico do "intelectual orgânico", não se tratava de propor saídas para as massas e de mostrar como se organizaria a nova sociedade, mas de perceber a mecânica do poder, denunciar a maneira como os micropoderes funcionam, como afetam nossos corpos, como produzem nossas subjetividades, para além das relações sociais de produção, para que pudessem ser driblados, desobedecidos e minimizados em seus efeitos destrutivos. Como observa Cesar Candiotto, analisando as resistências e insurreições em contraposição à noção de revolução, na filosofia foucaultiana:

Diante da constatação de que no presente sempre estamos diante de dispositivos de governamentalização da vida, a resistência a esse dispositivo governamental envolve colocá-lo em crise. Trata-se, pois, de valorizar o presente não como parte da cadeia linear da Revolução e sua promessa de retorno, mas a partir do esforço permanente de 'saída' de um estado atual no qual somos governados, destituídos de qualquer teleologia ou ideia de progresso (CANDIOTTO, 2013: 226).

Pode-se dizer que a questão maior de Foucault foi a de abrir as portas para um pensamento da diferença, capaz de diagnosticar o presente e de perceber imaginativamente outras possibilidades de resistência aos poderes e de criação da existência, inclusive subjetivas e psíquicas. Leitor e admirador de Gaston Bachelard, Foucault apostava na potência da imaginação criadora.

Essas questões foram muito mal compreendidas décadas atrás, já que no mesmo momento em que Foucault apontava para o sujeito em sua dimensão de "sujet", em francês, ou "súdito", enfatizando que o sujeito era também efeito do poder, a historiografia marxista trazia os muitos silenciados da História como protagonistas, agentes livres entendidos como construtores de sua própria história. O mesmo termo não dizia a mesma coisa: para uns, sujeito era sinônimo de liberdade individual, existia antes e acima da História, aliás, era a partir dele que se falava em ação, em pensamento e na ideologia; para outros, o sujeito estava inscrito num campo de relações de força, em jogos de poder e resistência em que era produzido e em que se produzia. O sujeito passava a ser problematizado e nasciam os conceitos de sujeição e de subjetivação.

O que ficou muito claro, de qualquer maneira, é que ele não se preocupava com o poder ou com a sexualidade por obsessão, limitação pessoal ou incapacidade de pensar a liberdade, mas que estranhava os temas privilegiados em nosso mundo, temas que fazem parte do foco central e do investimento da sociedade burguesa, como o poder e a sexualidade. E que se assustava com a nossa ingenuidade. Afinal, como contatava em entrevista realizada em 1982, "no final do século XIX, começa-se a ver emergir a importância do comportamento sexual na definição da individualidade. E isso é algo totalmente novo" (FOUCAULT, 2004b: 259).

O filósofo colocava um espelho muito irritante diante de nós mesmos e desagradava aos que não queriam perceber o que estava visível, a saber, que a sociedade moderna se preocupa acima de tudo com o desenvolvimento de inúmeras tecnologias de poder, governo e controle dos indivíduos e das populações, e que inclusive as práticas sexuais se transformaram em "dispositivos da sexualidade", como mais um passo nesse obsessivo investimento de controle dos corpos e de produção do "sujeito de desejo". 
Foucault já havia mostrado, nos volumes 2 e 3 da História da Sexualidade, que os antigos gregos e romanos se relacionavam diferentemente com o sexo, e que ao contrário do que pensávamos, nem sequer tinham o termo "sexualidade", que surge no início do século XIX, junto com a sciencia sexualis (FOUCAULT, 1984: 9). Não havia a centralidade do sexo instituída no imaginário burguês. Para os antigos gregos, o termo equivalente seria "aphrodisia" e remetia a outro núcleo de questões e de experiências. Marcando essa diferença entre antigos e modernos na relação de si para consigo, ele observava:

Um dos traços característicos da experiência cristã da 'carne', e posteriormente a da 'sexualidade', será a de que o sujeito é levado nessas experiências a desconfiar frequentemente, e a reconhecer as manifestações de um poder, surdo, ágil e temível que é tanto mais necessário decifrar quanto é capaz de se emboscar sob outras formas que não a dos atos sexuais. Uma tal suspeita não habita a experiência dos aphrodisia (FOUCAULT, 1984: 40).

Hoje, temos vários livros de história que mostram quando nasce a partilha entre heterossexualidade e homossexualidade, como A invenção da heterossexualidade, de Jonathan Ned Katz, ou Saint Foucault, de David Halpherin e inúmeras histórias da medicalização da sociedade e da patologização dos homossexuais, assim como de outras figuras consideradas "anormais". Dentre estas, destacamos as histórias das "perversões sexuais", noção inventada pelo psiquiatra alemão Richard von Krafft Ebbing, em 1886, ou ainda, dos onanistas, objeto do livro de Thomas Laqueur, Solitary Sex: A Cultural History of Masturbation (2003), que já nos havia presenteado com o importante trabalho Making Sex: Body and Gender from the Greeks to Freud (1992), traduzido em 2001, em que propunha uma ahistória da diferenciação sexual entre mulheres e homens. A admiração de Stephen Greenblatt pelo trabalho de Laqueur explicita-se na resenha que faz daquele livro:

O livro mais recente de Laqueur, Solitary Sex: A Cultural History of Masturbation, compartilha com Inventando o Sexo a mesma surpreendente premissa inicial: algo que damos por garantido, algo que é óbvio, algo que simplesmente parece ser parte do ser humano tem, de fato, uma história, e uma história fascinante, conflituosa e importante (GREENBLATT, 2004).

Lembro, ainda, que o pai da Antropologia criminal, o italiano Cesare Lombroso que, na década de oitenta, se tornava conhecido para além dos muros das conservadoras faculdades de Direito, passava progressivamente a ser estudado pelos/as historiadores/as do corpo, da sexualidade e das mulheres, e que ainda não havia se transformado em nome de shopping center, instalado no coração de São Paulo, aliás, na rua que leva seu próprio nome.

Ao trazer uma "história da diferença", apontando para as descontinuidades e rupturas que permitem "deslegitimar o presente", ou libertá-lo, mostrando que aquilo que é não resulta de uma necessidade histórica inscrita na ordem natural do mundo, não decorre de uma evolução histórica vista como progresso, como ensinara inclusive o marxismo tradicional, Foucault mostrou não só que o poder não era o foco central de preocupação de todas as sociedades, mas que, em nossa própria tradição ocidental, poderíamos encontrar exemplos de outros modos de vida, de outras concepções da cidadania e de produção da subjetividade, assim como da sociabilidade, que não visavam disciplinar os corpos e conduzir as condutas. Sem recorrer aos indígenas ou aos orientais, Foucault nos forçava a olhar para dentro, para nós mesmos; levava a entender, com sua proposta genealógica, não só onde tudo havia 
começado, onde a racionalidade e as formas do poder contemporâneo haviam se engendrado, como apontava para possíveis saídas, ao pluralizar os modos de vida que constituem nossa tradição e que se pautam por valores éticos. Foi inevitável perguntar por que não incorporamos o que de melhor nos oferece a nossa própria tradição.

Ora, olhar diferentemente para o nosso próprio passado, tendo em vista transformar o presente implicou fazer uso de outros conceitos, capazes de construir outras narrativas históricas e de dar visibilidade a determinadas práticas, e aqui desdobro o segundo ponto acima anunciado. Este foi o caso da noção de "disciplinas", apresentada em Vigiar e Punir, fundamental para construir uma história das prisões e da sociedade disciplinar, e posteriormente de muitos outros termos, como o de biopolítica, espiritualidade, governamentalidade, ou "condução das condutas" e o de contracondutas, esses últimos indispensáveis para pensar o neoliberalismo e as resistências, como aponta Maurício Pelegrini (2018).

Assim, para falar da liberdade, Foucault lançou mão da noção de "práticas da liberdade" que aparecem em vários momentos de sua obra, como nos dois volumes da História da Sexualidade, O uso dos prazeres e O cuidado de si, de 1984. Afinal, a formação do cidadão na Antiguidade clássica supunha a constituição de uma figura temperante, equilibrada, capaz de praticar livremente as "estéticas da existência" e o "cuidado de si" para atingir um domínio sobre si, o que estava longe de significar a mortificação do eu e a renúncia de si pregadas pelo cristianismo posteriormente. Ser livre das paixões, não ser escravo nem de si nem do outro não significava renunciar a si, viver em constante estado de culpa e evitar os prazeres, como afirma o cristianismo. Condenava-se o "stultus" como alguém que não sabia de si, que não se ocupava de si, que se deixava levar pelo vento, desorientadamente, sem vontade própria, como observa Foucault, remetendo a Sêneca:

A stultitia se define pela agitação da mente, pela instabilidade da atenção, pela mudança de opiniões e vontades, e consequentemente pela fragilidade diante de todos os acontecimentos que se podem produzir; caracteriza-se também pelo fato de dirigir a mente para o futuro, tornando-a ávida de novidades e impedindo-a de dar a si mesmo um ponto fixo na posse de uma verdade adquirida (FOUCAULT, 2004c:150).

Mas, no mundo pagão, não havia espaço para Tertuliano e Agostinho, nem para o poder pastoral, já que o indivíduo era formado acreditando que a verdade residia em seu próprio ser e que, portanto, não necessitava da figura do pastor para purificá-lo e conduzi-lo à salvação. $\mathrm{O}$ "atleta da espiritualidade antiga", diz Foucault, buscava trabalhar-se e preparar-se para os acontecimentos que poderiam vir à frente, tornando-se mais forte e mais sábio, ao contrário do "atleta cristão", que terá em si mesmo um inimigo constante a ser derrotado. "O atleta antigo é um atleta do acontecimento. Já o cristão é um atleta de si mesmo”, explica o filósofo (2004a: 399). Ainda não havia nascido a ideia de que o diabo habita o corpo de cada um nós; menos ainda, a definição do padre cristão Tertuliano, no século II dC, de que Eva seria "a porta do diabo".

Analisando minuciosamente esses deslocamentos nas formas da constituição de si, entre o mundo grego, o helenístico e o cristão, Thiago Calçado mostra, a partir de sua leitura de Foucault, como o cuidado com a vida, com o corpo e com o sexo, relacionados à cidade transforma-se, com os estoicos, em um cuidado de si voltado para uma interioridade. Já com o cristianismo, a ascese passa a caracterizar-se como uma relação de passividade e de formação da consciência culpada. Em suas palavras, 
O pathos sexual que os gregos viam na ordem de uma disposição com o meio ou com a própria vida em vista da arte de governar os outros é submerso na interioridade do ser cristão. Ele se transforma em um sujeito patético, marcado definitivamente pela concupiscência (CALÇADO, 2018: 197).

Talvez seja oportuno retornar ao tema da liberdade no pensamento de Foucault, lembrando que, nos últimos anos, foram publicados vários trabalhos, como Foucault, Feminismos e Subjetividade (2013), de Margaret McLaren, a coletânea Foucault e as Insurreições. É inútil revoltar-se? (2017), organizada por Silvio Gallo e Margareth Rago, Usos da Liberdade e Agonismo em Michel Foucault (2018), de Pedro Maurício Garcia Dotto, que encontram no filósofo o que apontara John Rajchman, em Foucault: a liberdade da Filosofia, de 1985.

No entanto, mesmo se nos limitássemos a discutir os momentos de sua obra em que fala literalmente da liberdade, o que não é nossa opção aqui, seria difícil entender que um autor que escreve sobre a história da loucura, ou sobre a história da sexualidade numa época em que se considerava que loucura e sexualidade não tinham história, porque se inscreveriam no campo da natureza, estava praticando sua própria forma da liberdade? Seria difícil entender que para abrir inúmeros temas de pesquisa e criar outros modos de pensar e de problematizar nossa atualidade e, portanto, toda a tradição que herdamos, são necessárias uma capacidade de voo, de ousadia e uma radicalidade impressionante, como atestam as produções de Foucault?

$\mathrm{Na}$ contramão de seu tempo, este filósofo intransigente, irônico e bem-humorado questionou os temas tradicionais que ocupavam a intelectualidade crítica, abriu inúmeros outros para reflexão e conhecimento, a exemplo do próprio sujeito, produzindo simultaneamente novos conceitos e cruzando os limites disciplinares, da história da medicina à psicologia, à literatura e à história cultural. Foucault revirou nossas formas de pensar, "sacudiu as evidências", estranhou o que era familiar, permitindo o contato com passados soterrados, até então inexistentes em nossa própria História, o que considerou fundamental para a crítica e a superação das condições do presente.

Tomemos, por exemplo, a difícil noção de "espiritualidade política", que Foucault apresenta no texto "A quoi rêvent les Iraniens?" (1978, 1994c), com a qual procurava entender as mobilizações populares no Irã, entre 1978 e 1979, sobre as quais produziu algumas reportagens. Entendida como "ópio do povo", a espiritualidade era descaracterizada como alienação e incompatibilizada com qualquer forma de motivação política. Na contramão dessa leitura, Maurício Pelegrini, em sua dissertação de mestrado defendida como "Michel Foucault e a Revolução Iraniana" (2015), enfrenta a noção de "espiritualidade política" como uma das principais inovações introduzidas no corpus teórico deste filósofo.

Ao contrário do que disseram seus críticos, entendendo que Foucault defendera o regime ditatorial de Khomeini, Pelegrini destaca a liberdade e o esforço da operação teórica do filósofo, na tentativa de perceber que certos movimentos de luta por novos formas de existência trazem exigências espirituais e subjetivas, que transcendem a estrita esfera do político. Para o filósofo, a revolução iraniana era "a primeira grande insurreição contra os sistemas planetários, a forma mais moderna da revolta e a mais louca" (FOUCAULT apud PELEGRINI, 2015: 132). A população dizia não ao xá Reza Pahlavi, recusando a forma de governo que lhe era imposta. Tratava-se, então, de abrir conceitualmente na política uma dimensão espiritual, desfazendo oposições binárias cristalizadas que inviabilizavam a compreensão da revolta e da insubmissão, vividas no movimento iraniano. Para Pelegrini, Foucault pode mostrar como "a vontade de mudar completamente a si mesmo interrompe o movimento contínuo da história, modificando também o regime de verdade ao qual o sujeito está submetido" (PELEGRINI, 2015: 131). 


\section{- o neoliberalismo e a subjetividade}

No final da década de 1970, no momento mesmo em que Ronald Reagan e Margaret Thatcher assumiam o poder, Foucault apresentava uma análise do neoliberalismo que só foi conhecida em 2004, quando seus cursos foram publicados em francês, e em seguida, traduzidos no Brasil, em 2008, como Nascimento da Biopolítica. Na contramão dos estudos marxistas sobre o neoliberalismo, que privilegiam a dimensão econômica, a reestruturação produtiva, a privatização e a perda dos direitos humanos, o que não deixa de ser importante, vale lembrar, Foucault propõe outra leitura do neoliberalismo enquanto governamentalidade neoliberal. Criando o conceito de "governamentalidade", ou "condução das condutas", como um poder pastoral atualizado, Foucault destaca a maneira pela qual a racionalidade neoliberal se difunde por todo o social, visando a generalização da forma econômica do mercado para todo o corpo social e resultando no que Wendy Brown (2015) denomina de "economização do social".

Assim, todas as esferas da vida em sociedade, inclusiva as relações que se travam na vida familiar e na intimidade passam a ser pensadas pela ótica do mercado, pelos mecanismos da concorrência. Nesse sentido, é a própria produção da subjetividade que se encontra no centro dessa arte neoliberal de governo, pois o indivíduo deve se pensar como um "empresário de si mesmo" e assumir todos os riscos para fazer existir esse empreendimento neoliberal. Diz Foucault:

É essa multiplicação da forma 'empresa' no interior do corpo social que constitui, a meu ver, o escopo da política neoliberal. Trata-se de fazer do mercado, da concorrência e, por conseguinte, da empresa o que poderíamos chamar de poder enformador da sociedade (FOUCAULT, 2008a: 203).

Ao analisar o neoliberalismo norte-americano, Foucault destaca a "teoria do capital humano", formulada pelo economista estadunidense Gary Becker, prêmio Nobel em Economia, em 1992, que visa a produção de uma nova forma de subjetividade empresarial e competitiva, o "empresário de si mesmo", "sendo ele próprio seu capital, sendo para si mesmo seu produtor, sendo para si mesmo a fonte de sua renda" (FOUCAULT, 2008a: 311). Sua análise minuciosa revela as mudanças epistemológicas propostas pela teoria neoliberal, que transforma o trabalhador em "sujeito econômico ativo", pois produtor de sua própria renda, o consumidor em "produtor de sua própria satisfação", chegando às relações do casal e da mãe com seu bebê, responsável pelo investimento formativo e educacional no capital humano de seus filhos.

Seguindo essa trilha, Christian Laval e Pierre Dardot, em A nova razão do mundo (2016), mostram que a governamentalidade neoliberal visa produzir o "neossujeito", ou o "empresário de si mesmo", envolvido com o investimento em seu "capital humano", isto é, em sua subjetividade, corpo, vida, para auferir uma renda no jogo concorrencial criado artificialmente pelo Estado. E apontam para as "contracondutas" como possibilidades de fazer frente a essas novas formas de controle.

A genealogia do sujeito moderno trabalhada por Foucault, ao longo de sua obra se vê ainda mais enriquecida com a publicação do último volume da História da Sexualidade, intitulado As confissões da carne, em vias de tradução. Nesse trabalho, Foucault aponta para dimensões profundamente enraizadas em nossa psique; afinal, trata-se da origem do que somos, das narrativas cristãs que constituíram a história do Ocidente, desde o primeiro homem, a primeira mulher e a invenção do pecado original, por Tertuliano e Agostinho, como historiciza brilhantemente Stephen Greenblatt, em Ascensão e Queda de Adão e Eva (2018).

A pesquisa arqueogenealógica de Foucault sobre os regimes de verdade que regem nossas vidas amplia-se consideravelmente ao abranger os primeiros anos do cristianismo e revelar a dívida que este mantém com o estoicismo, onde se encontram morais que não se destinavam a sujeitar o indivíduo, fazendo-o renunciar a si mesmo, como pregará o cristianismo, submetendo-se a normas, 
leis, códigos e regras pretensamente universais, impostos a todos em nome do bem comum. Naquele mundo, evidenciam-se estilos de vida, as "estéticas da existência", como traduz Foucault, em que a preocupação maior é da ordem da ética e da liberdade e não da obediência e da submissão.

Como mostra Tony Hara, em sua pesquisa de pós-doutoramento "Da Arte de Viver na Filosofia dos Espíritos Livres de F. Nietzsche e na Estética da Existência de M. Foucault", em andamento, esses filósofos foram fortemente afetados pelo caráter etopoético dos textos produzidos pelas escolas filosóficas da Antiguidade clássica. Esse saber essencialmente prático era voltado para a construção de um modo de vida ético, chamando o indivíduo a ocupar-se com a vida, desde as pequenas coisas. Obviamente, esses filósofos opunham-se veemente aos ensinamentos cristãos. Ao estudar a escola cínica, tão admirada por Foucault, Hara afirma:

A renúncia da vida, seja através da lâmina de um punhal ou através da evasão para um Paraíso além-vida qualquer, não é uma opção para os cínicos. O cínico se recusa a participar da festa dos suicidas, daqueles que renunciam a vida, a si mesmo e o mundo, em nome de um mundo imaginário, ungido, como diz Michel Onfray, "de todas as qualidades de pureza e de perfeição, desqualificando o mundo imediato e imanente, tido então como a casa dos impuros e dos degredados (HARA, 2017: 192).

Nessa direção, Foucault faz instigantes reflexões sobre os deslocamentos da ascese antiga para a cristã e mostra a migração da confissão, percebida como uma tecnologia do poder pois supõe a submissão ao olhar do outro, e do poder pastoral para fora dos muros da igreja e para sua incorporação no Estado moderno, chegando aos nossos dias, marcados pelo neoliberalismo. Em suas palavras,

O Estado pode ser considerado como uma nova forma do poder pastoral, a matriz moderna da individualização (...) O poder pastoral ampliou-se subitamente por todo o corpo social; encontrou apoio numa multiplicidade de instituições (FOUCAULT,1995: 238).

Assim, Foucault estabelece uma ponte de continuidade entre o neoliberalismo e o cristianismo, em que pesem as descontinuidades. Como observa o psicanalista Aldo Ambrózio, estudando o gerenciamento da vida e a produção da subjetividade no neoliberalismo:

Ironias à parte, tal processo de empresariamento de si nos parece se assemelhar, ao menos em um aspecto, ao princípio da pastoral cristã no modo como os sujeitos que por ele são capturados tem conduzidos seus cotidianos nesse momento de governamentalidade neoliberal: uma obediência total e cega aos princípios de competição anunciados pelo Deus ex machina do mercado criado e protegido por uma rígida e contínua intervenção dos Estados contemporâneos. Não parece ser à toa que esse novo tipo de crença religiosa grassou nesse período de governamentalidade neoliberal (AMBRÓZIO, 2011: 117).

\section{- feminismos e contracondutas}

A filosofia de Foucault também trouxe importantes contribuições para que os "estudos feministas" aprofundassem sua crítica do presente, denunciando o patriarcado e as racionalidades masculinas e misóginas. Sobretudo desde os anos noventa, quando se introduz a categoria do gênero no Brasil e os "estudos feministas" se abrem para a filosofia da 
diferença, é produzida uma gama enorme de trabalhos, em que se tornam conhecidas as críticas de feministas como Judith Butler, Rosi Braidotti, Elisabeth Grosz, Johanna Oksala, Tania N. Swain, Heloísa Buarque de Hollanda, Norma Telles, Rita Segato, Dora Barrancos, entre outras. Para os fins desse artigo, sugiro uma consulta à revista Labrys, Estudos Feministas, de orientação pós-estruturalista e foucaultiana, e também a outras revistas que atestam a qualidade da crítica feminista, no país e no exterior.

Considerando a historiografia feminista brasileira de inspiração foucaultiana, destaco alguns trabalhos que mostram como a desobediência e a insubmissão femininas têm afetado, desestabilizado e transformado a cultura masculina, no mundo ocidental. Valendo-se da noção de "contracondutas", entre outras, esses estudos mostram como as mulheres têm produzido rupturas nas formas sociais e culturais hegemônicas e na própria maneira de constituírem-se subjetivamente. Afinal, pelo menos nos últimos cinquenta anos, os feminismos produziram novos modos de subjetivação, abriram outros possibilidades de existir, propuseram novas interpretações com suas críticas contundentes à cultura masculina e misógina dominante e trouxeram modos de inscrição na esfera pública ou privada, pautados por valores de justiça social, liberdade, respeito à dignidade e solidariedade.

Destaco o livro de Marilda Ionta, As cores da amizade: cartas de Anita Malfatti, Oneyda Alvarenga, Henriqueta Lisboa e Mário de Andrade (2007), que aponta para outra concepção de amizade e de amizade entre as mulheres, para além das referências restritivas do privado herdadas do cristianismo, que inviabilizam noções de solidariedade no público. Ana Carolina Arruda de Toledo Murgel, na tese de doutorado intitulada "Navalhanaliga: a poética feminista de Alice Ruiz" (2010), analisa como se dá a construção da subjetividade dessa compositora e poeta, a partir de suas experiências e práticas estéticas. Essa autora feminista possui, além disso, inúmeros artigos, em que nos apresenta a produção musical das compositoras brasileiras, em geral, silenciadas ou depreciadas nas histórias da música popular, em geral, escrita pelos homens.

Luana Saturnino Tvardovskas, por sua vez, no livro Dramatização dos corpos: arte contemporânea de mulheres no Brasil e Argentina (2013), trabalha com a poética visual das artistas brasileiras Ana Miguel, Rosana Paulino e Cristina Salgado e das argentinas Silvia Gai, Claudia Contreras e Nicola Costantino, mostrando que suas obras de arte empreendem um discurso crítico à violência material e simbólica de gênero, por meio de imagens do corpo. Referenciando-se pelos conceitos foucaultianos e pela perspectiva feminista, destaca como essas artistas se utilizam de transfigurações, dramatizações e manipulações sobre imagens corporais como manobras transgressivas e de resistência, que desestabilizam representações cristalizadas no imaginário social.

No meu caso, a crítica de Foucault à narrativa confessional e a noção diferenciada de "escrita de si", que ele apresenta ao falar dos antigos gregos foram fundamentais para a produção de A Aventura de contar-se: feminismos, escrita de si e invenções da subjetividade (2013). Procurei mostrar, a partir do recurso às autobiografias escritas ou produzidas oralmente em entrevistas por sete feministas conhecidas, como sobreviveram na luta contra um mundo desigual, misógino e excludente, seja quando foram presas ou exiladas, nos anos setenta, seja quando perseguiram outras trajetórias, desobedecendo, subvertendo as regras e escapando das imposições normativas. Perguntei como conseguiram reinventar-se subjetivamente, dando saídas éticas, estéticas e políticas para suas próprias vidas, demonstrando uma coragem cínica da verdade. Concluí, nesse percurso de pesquisa, que o "cuidado de si" exercido por elas a partir de "práticas da liberdade", levado a cabo ao longo de décadas, foi fundamental para o cuidado com o outro, com a outra e com a cidade, como praticam até hoje. Nesse sentido, os conceitos foucaultianos foram fundamentais para dar visibilidade àquilo que, a meu ver, exigia ser nomeado e historicizado. Ao mesmo tempo, fazia eco à afirmação de Foucault de que se fora esquecido pelos livros de História da 
Filosofia, a filosofia cínica havia chegado aos movimentos revolucionários de que somos herdeiros/as. Segundo ele,

O cinismo, a ideia de um modo de vida que seria a manifestação irruptiva, violenta, escandalosa, da verdade faz parte e fez parte da prática revolucionária e das formas assumidas pelos movimentos revolucionários ao longo do século XIX. A revolução no mundo europeu moderno (...) não foi um simplesmente um projeto político, foi também uma forma de vida. Ou, mais precisamente, ele funcionou como um princípio que determinava um modo de vida (...) (FOUCAULT, 2011a: 161).

Mais recentemente, Marilea de Almeida defendeu sua tese de doutorado intitulada "Território de Afetos: práticas femininas antirracistas nos quilombos contemporâneos do Rio de Janeiro" (2018), fortemente referenciada pelas reflexões de Foucault e por um de seus leitores mais destacados na atualidade, Achille Mbembe, autor de Crítica da Razão Negra e Necropolítica, traduzidos no Brasil, em 2018. A pesquisa dessa historiadora, realizada em vários quilombos do Rio de Janeiro, revela como a demonização da mulher desde Eva, considerada como a responsável pela queda, como afirmam os primeiros padres cristãos, se estende aos negros e sobretudo às negras, radicalmente excluídos/as de toda forma de humanidade, no pensamento ocidental. Por outro lado, a noção de "contracondutas" permite-lhe destacar que as criações femininas das mulheres quilombolas, desde a década de 1980, comportam outros modos de fazer política, especialmente em sua dimensão da luta contra os "dispositivos da racialidade" em diversas frentes como a educação, a religiosidade e a formação política.

\section{Concluindo: as marcas da pantera se ampliam e se difundem}

Vinte e cinco anos depois, Foucault continua a nos surpreender com suas ousadas reflexões, ainda em vias de serem conhecidas, mas também continuam a nos surpreender os/as pesquisadores/as que têm produzido livros, artigos e ensaios admiráveis, fazendo uso da extensa caixa de ferramentas que esse filósofo disponibiliza. Ao contrário do que acontecia década atrás, Foucault já não irrita com sua ironia e provocações; ao contrário, é bem vindo com seus operadores e problematizações, que nos dão instrumentos potentes para enfrentar um mundo muito mais complexo e difícil.

$\mathrm{O}$ acesso às obras inéditas de Michel Foucault, no século XXI, confirma que as "marcas da pantera" vieram para ficar, e que, na verdade, a pantera é realmente muito mais poderosa, crítica, questionadora e subversiva do que pensávamos. Além do mais, não seria nenhuma novidade observar que a pantera deu suas crias e que suas marcas se renovaram e pluralizaram, atestando enorme vigor e uma feliz explosão de criatividade, especialmente das gerações que nos sucederam. Com licença de Gilberto Gil, aqui é Foucault quem nos dá "régua e compasso" e "aquele abraço"...

\section{Referências}

AMBRÓZIO, Aldo. Empresariamento da vida. A função do discurso gerencialista nos processos de subjetivação inerentes à governamentalidade neoliberal. Curitiba: Editora e Livraria Appris Ltda, 2018.

BROWN, Wendy. Undoing the Demos. Neoliberalism's Stealth Revolution. New York: Zone Books, 2015. 
CALÇADO, Thiago. Entre a carne e o verbo. Confissão, sexualidade e discurso em Michel Foucault. São Paulo: Gênio Criador Editora, 2017.

CANDIOTTO, Cesar. "Política, revolução e insurreição em Michel Foucault”, Revista de

CORBIN, Alain. Histoire du Silence: de la Renaissance à nos jours, Paris: Albin Michel, 2016.

CORBIN, Alain. La Douceur de l'ombre. L'arbre source d'émotion, de l'Antiquité à nos jours. Paris: Fayard, 2013.

CORBIN, Alain. Le miasme et la jonquille: L'odorat et l'imaginaire social, XVIIIe-XIXe Siècles. Paris: Flammarion, 1982.

DARDOT, Pierre; LAVAL, Christian. A nova razão do mundo. São Paulo: Boitempo, 2016.

Filosofia Aurora, v. 25, n. 37, 2013, pp. 223-242.

FOUCAULT, Michel. «Uma entrevista com Michel Foucault», Verve, Revista do NU-SOL da PUC-SP, n.5, 2004d, pp. 240-259.

FOUCAULT, Michel. “A cena da filosofia”. Ditos e Escritos, vol. VIII, Org. Manoel Barros da Motta, Trad. Vera Lucia Avellar Ribeiro, 2011b, pp. 222-247.

FOUCAULT, Michel. “A Escrita de Si”, Ditos e Escritos, vol. V. Ética, sexualidade, política. Organização de Manoel Barros da Motta. Trad. Elisa Monteiro, Inês Autran Dourado Barbosa. Rio de Janeiro: Forense Universitária, 2004c, pp. 144-162.

FOUCAULT, Michel. "La philosophie analytique de la politique". Dits et Écrits, T. III. Paris: Gallimard, 1994a, pp.534-551.

FOUCAULT, Michel. "Michel Foucault, uma entrevista: sexo, poder e a política da identidade". Trad. Wanderson Flor do Nascimento, Verve, Revista do NU-SOL da PUC-SP, n. 5, 2004b, pp.260-277.

FOUCAULT, Michel. "Nietzsche, a Genealogia e a História", Microfísica do Poder. Trad. Roberto Machado. Rio de Janeiro: Graal, 1979.

FOUCAULT, Michel. “O que são as Luzes?” Ditos e Escritos VIII. Organizador Manoel Barros da Motta. Trad. Elisa Monteiro. Rio de Janeiro: Forense Universitária, 2011c, pp. 259268.

FOUCAULT, Michel. "O sujeito e o poder". In: RABINOW, P.; DREYFUS, H. Foucault, uma trajetória filosófica. Para além do estruturalismo e da hermenêutica. Trad. Vera Portocarrero. Rio de Janeiro: Forense Universitária, 1995, pp. 231-249.

FOUCAULT, Michel. "Outros espaços". Ditos e Escritos, vol. III. $3^{\text {a } . e d . T r a d . ~ I n e ̂ s ~ A u t r a n ~}$ Dourado. Barbosa. Rio de Janeiro: Forense Universitária, 2013, p.414-424.

FOUCAULT, Michel. A Coragem da Verdade: O Governo de Si e dos Outros. Vol. II. Trad. Eduardo Brandão. São Paulo: Martins Fontes, 2011a. 
FOUCAULT, Michel. A Hermenêutica do Sujeito. Trad. Salma Tannus Muchail e Márcio Alves da Fonseca. São Paulo: Martins fontes, 2004a.

FOUCAULT, Michel. Do Governo dos Vivos. Trad. Eduardo Brandão. São Paulo: Martins Fontes. 2014.

FOUCAULT, Michel. Histoire de la Sexualité. Vol. 4. Les Aveux de la Chair. Paris: Gallimard, 2018.

FOUCAULT, Michel. Nascimento da Biopolítica. Trad. Eduardo Brandão. São Paulo: Martins Fontes, 2008a.

FOUCAULT, Michel. Segurança, Território e População. Trad. Eduardo Brandão. São Paulo: Martins Fontes, 2008b.

FOUCAULT, Michel. Vigiar e Punir. Nascimento da Prisão. Trad. Lygia M. Pondé Vassallo. Petrópolis: Editora Vozes, 1977.

FOUCAULT, Michel. «A quoi rêvent les Iraniens? », Dits et Écrits, T. III. Paris: Gallimard, 1994c, pp. 668-694.

FOUCAULT, Michel. "L'éthique du souci de soi comme pratique de la liberté". Dits et Écrits, T. IV. Paris: Gallimard, 1994b, pp.708-729.

FOUCAULT, Michel. História da Sexualidade- II. O uso dos prazeres. Rio de Janeiro: Graal, 1984.

GRABOIS, Pedro F. "Resistência e revolução no pensamento de Michel Foucault: contracondutas, sublevações e lutas", Cadernos de Ética e Filosofia Política 19, 2/2011, pp.07-27.

GREENBLATT, Stephen. "Me, Myself, and I". The New York Review of Books, april 2004. Disponível em: https://www.nybooks.com/articles/2004/04/08/me-myself-and-i

GREENBLATT, Stephen. Ascensão e Queda de Adão e Eva. São Paulo: Companhia das Letras, 2018.

HARA, Tony. "Da Arte de Viver na Filosofia dos Espíritos Livres de F. Nietzsche e na Estética da Existência de M. Foucault", Projeto de Pós-doutoramento, Programa de Pósgraduação em História do IFCH da UNICAMP, 2018.

IONTA, Marilda. As cores da amizade: cartas de Anita Malfatti, Oneyda Alvarenga, Henriqueta Lisboa e Mário de Andrade. São Paulo: Annablume; Fapesp, 2007.

LAQUEUR, Thomas. Inventando o sexo dos gregos à Freud. Rio de Janeiro: Relume Dumará, 2001.

LAQUEUR, Thomas. Solitary Sex: A cultural history of masturbation, Zone Books, 2003.

McLAREN, Margaret. Feminismo, Foucault e a Subjetividade. São Paulo: Intermeios, 2016. 
PELEGRINI, Maurício. "Foucault e a sociedade neoliberal: o trabalhador como 'empresário de si"”. In: TONETTI, Ana C.; NOBRE, Ligia V.; MARIOTTI, Gilberto; BAROSSI, Joana. Contracondutas. São Paulo: Associação Escola da Cidade, Arquitetura e Urbanismo, 2017, pp. 97-107.

PELEGRINI, Maurício. "Michel Foucault e a Revolução Iraniana”, dissertação de mestrado, Programa de Pós-graduação em História do IFCH da UNICAMP, 2015.

RAGO, Margareth. "As marcas da pantera: Foucault para historiadores”, Revista Resgate, Centro de Memória da UNICAMP, Campinas, 1993, pp. 22-33.

RAGO, Margareth. A aventura de contar-se: feminismos, escrita de si e invenções da subjetividade. Campinas, SP: Editora da Unicamp, 2013. https://doi.org/10.7476/9788526814691

RAGO, Margareth; GALLO, Silvio. Foucault e as Insurreições. É inútil revoltar-se? São Paulo: Intermeios, 2017, pp. 363-374.

RAJCHMAN, John. Foucault: a liberdade da Filosofia, tradução de Álvaro Cabral. Rio de Janeiro: Jorge Zahar Editor, 1985. 